\title{
Requirements for Xenon International
}

Prepared for the U.S. Department of State under the award EAIAA DOS-IAA-12-ISN/NDF02 "Development of a Next Generation Xenon Monitoring System (aka Xenon International)"

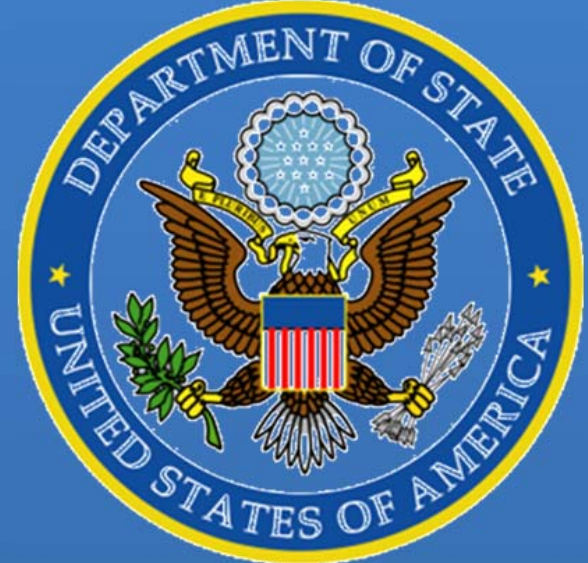

September 26, 2013 


\title{
DISCLAIMER
}

This report was prepared as an account of work sponsored by an agency of the United States Government. Neither the United States Government nor any agency thereof, nor Battelle Memorial Institute, nor any of their employees, makes any warranty, express or implied, or assumes any legal liability or responsibility for the accuracy, completeness, or usefulness of any information, apparatus, product, or process disclosed, or represents that its use would not infringe privately owned rights. Reference herein to any specific commercial product, process, or service by trade name, trademark, manufacturer, or otherwise does not necessarily constitute or imply its endorsement, recommendation, or favoring by the United States Government or any agency thereof, or Battelle Memorial Institute. The views and opinions of authors expressed herein do not necessarily state or reflect those of the United States Government or any agency thereof.

\author{
PACIFIC NORTHWEST NATIONAL LABORATORY \\ operated by \\ BATTELLE \\ for the \\ UNITED STATES DEPARTMENT OF ENERGY \\ under Contract DE-AC05-76RL01830
}

Printed in the United States of America

Available to DOE and DOE contractors from the

Office of Scientific and Technical Information,

P.O. Box 62, Oak Ridge, TN 37831-0062;

ph: (865) 576-8401

fax: $(865) 576-5728$

email: reports $a$ adonis.osti.gov

Available to the public from the National Technical Information Service

5301 Shawnee Rd., Alexandria, VA 22312

ph: (800) 553-NTIS (6847)

email: $\operatorname{orders} a$ ntis.gov $<$ http://www.ntis.gov/about/form.aspx $>$

Online ordering: http://www.ntis.gov

This document was printed on recycled paper.

(8/2010) 


\section{DOCUMENT AVAILABILITY}

Online Access: U.S. Department of Energy (DOE) reports produced after 1991 and a growing number of pre-1991 documents are available free via DOE's SciTech Connect (http://www.osti.gov/scitech)

Reports not in digital format may be purchased by the public from the National Technical Information Service (NTIS):

U.S. Department of Commerce

National Technical Information Service

5301 Shawnee Rd

Alexandra, VA 22312

www.ntis.gov

Phone: (800) 553-NTIS (6847) or (703) 605-6000

Fax: (703) 605-6900

Email: orders@,ntis.gov

Reports not in digital format are available to DOE and DOE contractors from the Office of Scientific and Technical Information (OSTI):

U.S. Department of Energy

Office of Scientific and Technical Information

P.O. Box 62

Oak Ridge, TN 37831-0062

www.osti.gov

Phone: (865) 576-8401

Fax: (865) 576-5728

Email: reports@osti.gov 


\section{Contents}

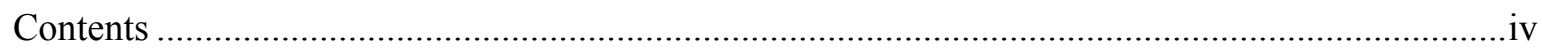

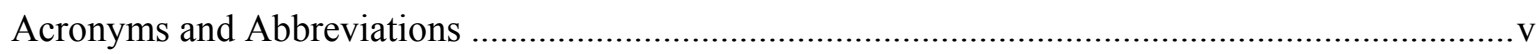

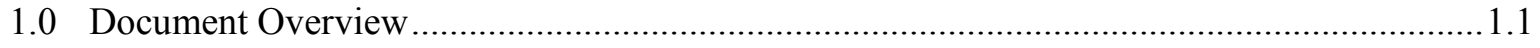

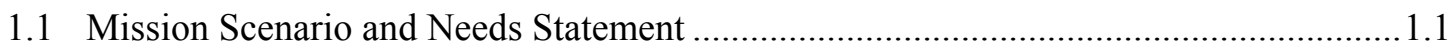

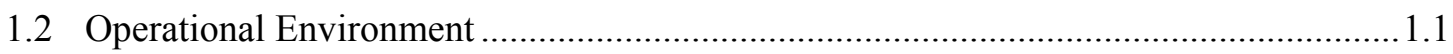

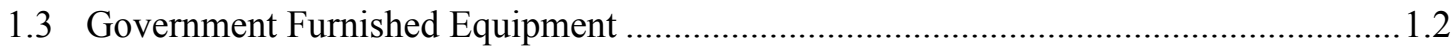

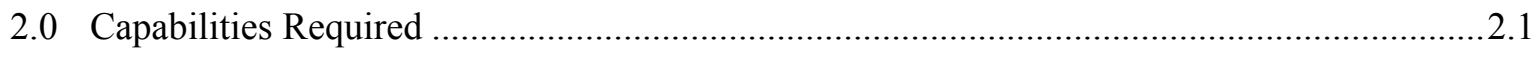

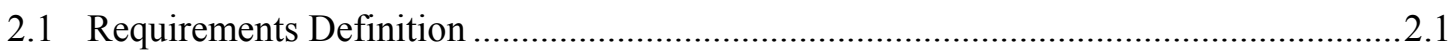

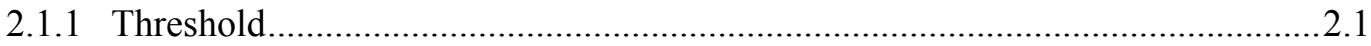

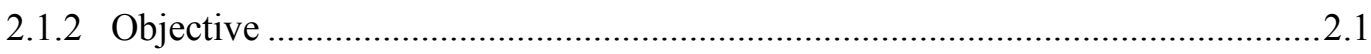

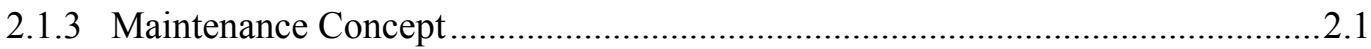

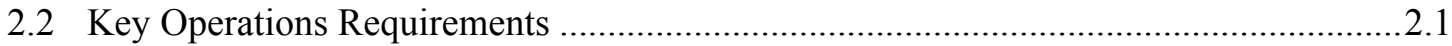

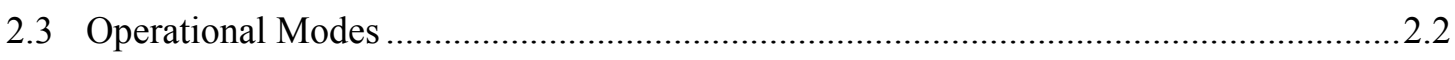

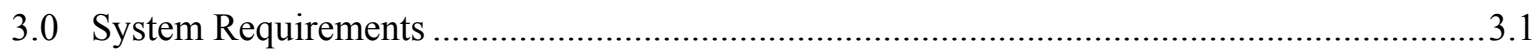

\section{Tables}

Table 2.1. Summary of Key Operations Requirements ................................................................2.2

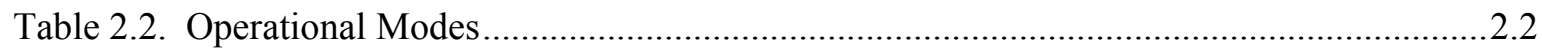


ASTM

$\mathrm{C}_{\mathrm{MX}} \mathrm{t}_{\mathrm{MX}}$

Cs

Co

$\mathrm{CO}_{2}$

FMC

FWHM

GFE

GUI

$\mathrm{H}_{2} \mathrm{O}$

INGE

MDC

MTBCF

MTBF

MTTR

$\mathrm{N}_{2} \mathrm{O}$

NDC

NTP

$\mathrm{Pb}$

PHS\&T

PMC

PNNL

QA/QC

QC

$\mathrm{Rn}$

ROI

SCP

SFTP

SMTP

$\mathrm{SOH}$

$\mathrm{SSH}$

STP

UPS

UTP

$\mathrm{Xe}$

\section{Acronyms and Abbreviations}

American Society for Testing and Materials

maximum corrective maintenance time

cesium

cobalt

carbon dioxide

fully mission capable

full width at half maximum

government-furnished equipment

graphical user interface

water

International Noble Gas Experiment

minimal detectable concentrations

mean time between critical failures

mean time between failures

mean time to repair

nitrous oxide

National Data Center

network protocol

lead

packaging, handling, shipping, and transportation

partially mission capable

Pacific Northwest National Laboratory

quality assurance/ quality control

quality control

radon

region of interest (The region within a beta-gamma spectrum that contains the sample counts used in calculating the activity.)

secure copy

secure shell (SSH) file transfer protocol

simple mail transfer protocol

state of health

secure shell

standard temperature and pressure - a temperature of $273.15 \mathrm{~K}\left(0 \mathrm{C}, 32^{\circ} \mathrm{F}\right)$ and an absolute pressure of $100 \mathrm{kPa}(14.504 \mathrm{psi}, 0.986 \mathrm{~atm}, 1 \mathrm{bar})$.

uninterruptable power supply

unshielded twist pair

xenon 



\subsection{Document Overview}

This document defines the requirements for the new Xenon International radioxenon system to measure radioactive xenon concentrations in the atmosphere. The output of this project will be two closely matching prototypes - one developed by the Pacific Northwest National Laboratory (PNNL) and one developed by a manufacturer. Overlapping development cycles and open communication between PNNL and the manufacturer will facilitate the close match of the two prototypes.

This document contains requirements for the manufacturer production system. These requirements will be useful to develop a complete technical specification for production systems incorporating the lessons learned during prototype development and testing. Each requirement will be verified during test and evaluation of the prototype systems, and lessons learned incorporated into the technical specification and design of production systems.

The Xenon International system has a lifetime goal of 10-15 years. This takes into account that some of the parts will need to be maintained and replaced during that time. This is a design and planning goal rather than a manufacturing requirement as years of field experience are not yet available to verify the expected lifetime of the system.

\subsection{Mission Scenario and Needs Statement}

The Xenon International system will be installed in a fixed location and will operate 24 hours per day, 7 days per week to measure radioactive xenon concentrations in the atmosphere. The hardware and software will be sharable for their intended use of treaty monitoring.

Detection of xenon isotopes is a proven and important method for distinguishing nuclear explosions from earthquakes and is particularly well suited to detecting undeclared underground testing. The radioxenon isotopes ${ }^{131 \mathrm{~m}} \mathrm{Xe},{ }^{133} \mathrm{Xe},{ }^{133 \mathrm{~m}} \mathrm{Xe}$ and ${ }^{135} \mathrm{Xe}$ are of particularly high value in identifying nuclear explosions and thus are the focus of current noble gas detection systems. A Xenon International system will incorporate the important lessons learned during the previous ten-year International Noble Gas Experiment (INGE). Redesigned subsystems will increase sensitivity to minor xenon isotopes, increase sampling frequency, and improve system reliability and performance, all of which are the main drivers of this new system. The presence of an improved xenon monitoring system will increase ability to detect and distinguish nuclear explosion activity.

\subsection{Operational Environment}

The system will be installed and operated indoors in a building or facility that will provide access to outdoor air for sampling. The system will obtain electrical power from the building. It is assumed the system will be operated in a lockable room that will allow easy access for operation and maintenance. Storage shall be available for the consumables, tools, and spare parts deemed necessary to operate and maintain the system. There will be no radioactive sources that can interfere with the system measurement capability and lead to a false spectrum interpretation. If sources are stored near the system, they shall be properly shielded. 
The indoor (ambient) temperature of the room housing the system shall remain within the operational temperature range of the system components with humidity between 50 and 80 percent.

This document contains the requirements necessary to manufacturer a Xenon International system. Requirements that pertain exclusively to external systems such as an archiving system, uninterruptable power supply (UPS), or authentication hardware are outside the scope of this document. Similarly, calibration or certification requirements are outside the scope of the manufacturing requirements.

\subsection{Government Furnished Equipment}

The following is a list of government furnished equipment (GFE) provided for the development and production of the manufacturer-developed production prototype. The hardware provided is anticipated to be a long-lead time and is intended to be used only on the manufacturer-developed production prototype to ensure the schedule is maintained. The only items provided intend to be GFE for production units are the software and software design description. The GFE includes:

1. Control software executables and source code

2. Software design description

3. High-voltage power supply for the radioxenon detectors

4. Micro channel recuperator heat exchangers. 


\subsection{Capabilities Required}

\subsection{Requirements Definition}

This section defines terms used within some of the system requirements found in Section 3.

\subsubsection{Threshold}

A threshold is a minimum acceptable capability or value for a system characteristic that is necessary to provide the operational capability that satisfies the mission need. Unless otherwise noted, all requirements in this document are thresholds.

\subsubsection{Objective}

An objective is a capability or value beyond the threshold that could have a measurable and beneficial impact on the system performance, supportability, or operational concept of employment. It is that value or capability desired by the user, which the system is ultimately attempting to obtain. An objective is a cost-effective increment above the threshold for each program capability and represents a desire for performance.

\subsubsection{Maintenance Concept}

The Xenon International maintenance concept consists of the following levels of maintenance:

- On-site Maintenance: consists of those maintenance tasks normally performed on-site.

- Depot Maintenance: consists of those tasks performed using highly specialized skills, sophisticated shop equipment, or special facilities of a supporting directorate; commercial activity (sending part(s) or component(s) to the supplier or manufacturer); or inter-service agency, at specialized repair centers, centralized repair facilities, or in some cases at an operating location.

\subsection{Key Operations Requirements}

Xenon International will have increased capability (increased sensitivity to minor xenon isotopes, increased sampling frequency, and improved system reliability and performance), compared to currently fielded systems. Table 2.1 displays a summary of some of the key requirements of the system that will be detailed further in the following sections. 
Table 2.1. Summary of Key Operations Requirements

\begin{tabular}{|c|c|c|}
\hline Characteristics & Minimum Requirements & Requirement ID \\
\hline Collection time & $\leq 8$ hours (threshold),$\leq 6$ hours (objective) & R 1.1 .3 \\
\hline Measurement time & $\leq 24$ hours & R 2.2 .9 \\
\hline Time before reporting & $\leq 48$ hours & R 1.3 .3 \\
\hline Reporting frequency & daily & $\mathrm{R} 4.1 .10$ \\
\hline Isotopes measured & ${ }^{131 \mathrm{~m}} \mathrm{Xe},{ }^{133 \mathrm{~m}} \mathrm{Xe},{ }^{133} \mathrm{Xe},{ }^{135 \mathrm{~m}} \mathrm{Xe}$ & $\mathrm{R} 1.2 .5$ \\
\hline $\begin{array}{l}\text { Minimum Detectable } \\
\text { Concentration }\end{array}$ & $\begin{array}{l}\text { For }{ }^{133} \mathrm{Xe},{ }^{133 \mathrm{~m}} \mathrm{Xe} \text {, and }{ }^{131 \mathrm{~m}} \mathrm{Xe}: 0.3 \mathrm{mBq} / \mathrm{m}^{3} \text { (threshold), } 0.15 \mathrm{mBq} / \mathrm{m}^{3} \\
\text { (objective); For }{ }^{135} \mathrm{Xe} 1.0 \mathrm{mBq} / \mathrm{m}^{3} \text { (threshold), } 0.5 \mathrm{mBq} / \mathrm{m}^{3} \text { (objective) }\end{array}$ & $\mathrm{R} 2.2 .2$ \\
\hline State of health & status data transmitted to the National Data Center (NDC) & $\mathrm{R} 4.1 .1 .4$ \\
\hline Communication & two-way & R 3.1 .1 \\
\hline Data availability & $95 \%$ & $\mathrm{R} 4.1 .1$ \\
\hline Down time & $\leq 7$ consecutive days; $\leq 15$ days annually & R 8.1 .1 \\
\hline Size and Weight & $\begin{array}{l}\leq 40 \text { " wide } \times 32 \text { " deep x } 80 \text { " high and } \leq 3000 \text { pounds (threshold) }, \leq \\
2500 \text { pounds (objective) }\end{array}$ & R 6.1.1/ R 6.1 .2 \\
\hline Power & $\begin{array}{l}\text { Single phase domestic power (threshold) and foreign power } \\
\text { (objective) }\end{array}$ & R 6.3 .1 \\
\hline Measurement Mode & Beta-Gamma coincidence & R 2.1.1 \\
\hline
\end{tabular}

\subsection{Operational Modes}

The system shall allow for the modes of operation detailed in Table 2.2.

Table 2.2. Operational Modes

\begin{tabular}{ll}
\hline Mode & Required Functionality \\
\hline Fully Mission Capable (FMC) & Full function operation \\
Partially Mission Capable (PMC) & $\begin{array}{l}\text { Less than full capability, but able to produce results at least intermittently } \\
\text { (for example, operating with a failed sensor or nuclear detector) }\end{array}$ \\
Regeneration & $\begin{array}{l}\text { The system must be fully regenerated and ready to start collection within } \\
8 \text { hours }\end{array}$ \\
Shutdown Mode & Emergency and controlled shutdowns shall be operational when necessary \\
Maintenance & Maintenance is performed on the system \\
Failure & The system is unable to collect or record data \\
\hline
\end{tabular}




\subsection{System Requirements}

The Xenon International system requirements are as follows. Functions are indicated with F, and requirements are indicated by R. Note: requirements in bold are the Key Operations Requirements listed in Table 2.1.

F 1 Gas Processing

\section{F 1.1 Collection}

R 1.1.1 The system shall be an automated, unattended system that continuously collects whole air from the atmosphere 24 hours a day/7 days a week.

R 1.1.2 The system shall automatically collect, process, transfer, and analyze xenon gas without human intervention.

R 1.1.3 The system shall support continuous collection of xenon from the atmosphere with cycle times of 8 hours (threshold), 6 hours (objective).

R 1.1.4 The system shall dry the air to a dew point of at least $-85^{\circ} \mathrm{C}(\mathrm{STP})$.

R 1.1.5 The system shall contain a certified precision flow meter to monitor the stability of the air flow. The precision of the measured flow rate shall be equal or better than $10 \%$. The certification requirement may be satisfied through calibration at the manufacturer and verified with the certification documentation that comes with the sensor.

R 1.1.6 The system shall remove impurities, such as water vapor $\left(\mathrm{H}_{2} \mathrm{O}\right)$, and carbon dioxide $\left(\mathrm{CO}_{2}\right)$ for the entire duration of the collection process.

R 1.1.7 The system shall have a collection efficiency of greater than or equal to $65 \%$ (threshold), 75\% (objective).

R 1.1.8 The system shall have a stable xenon collection efficiency that varies no more than $10 \%$ during a sampling cycle.

R 1.1.9 The sampling cycles for the Xenon International system shall be of the same duration within $\pm 10 \%$.

\section{F 1.2 Processing}

R 1.2.1 The system shall perform on-site gas processing of xenon from the whole air collection.

R 1.2.2 The system shall remove impurities such as nitrous oxide $\left(\mathrm{N}_{2} \mathrm{O}\right)$ for the entire duration of the collection process. 
R 1.2.3 The system shall use nitrogen gas bottles (threshold) or a nitrogen generator in combination with nitrogen gas bottles (objective). If only using nitrogen bottles, no more than 2 bottles per month shall be used (bottle containing $7.22 \mathrm{~m}^{3}$ or $225 \mathrm{ft}^{3}$ of nitrogen). If a combination nitrogen generator/nitrogen bottles are used, no more than 1 nitrogen bottle in 6 months shall be used.

R 1.2.4 The system shall remove radon $(\mathrm{Rn})$ greater than a factor of $10^{7}$ from the processing stream as $\mathrm{Rn}$ causes significant interference with the nuclear measurement of the target xenon isotopes.

R 1.2.5 The system shall separate xenon gas from the whole air and measure the following isotopes: ${ }^{133} \mathrm{Xe},{ }^{131 \mathrm{~m}} \mathrm{Xe},{ }^{133 \mathrm{~m}} \mathrm{Xe}$, and ${ }^{135} \mathrm{Xe}$.

$\mathrm{R}$ 1.2.6 The system shall deliver a minimum total volume of $1 \mathrm{cc}$ of stable xenon at STP conditions over a period of 8 hours in the measuring cell.

R 1.2.7 The cross contamination between samples shall be less than $1 \%$, i.e. less than $1 \%$ of a sample shall be carried over to a subsequent sample. This requirement does not address the memory effect in the measurement cells. The memory effect is addressed in section F 2.2 Nuclear Detection Count.

\section{F 1.3 Quantification}

R 1.3.1 The system shall include a gas analysis system which is capable of determining the volume of xenon gas (volume at STP) in the measurement cell with an uncertainty of $10 \%$ or better.

R 1.3.2 The calculations for the $\mathrm{Xe}$ volume uncertainty measurement shall be documented.

$\mathbf{R}$ 1.3.3 The system shall report a measurement value at the end of acquisition and within 48 hours after the start of collection.

F 2 Nuclear Detection

R 2.1.1 The Xenon International system shall use a beta-gamma coincidence detector.

\section{F 2.2 Count}

R 2.2.1 The system shall carry out a gas background measurement prior to each sample cycle measurement.

R 2.2.2 The system shall perform measurements of radioxenon activity concentrations in a background environment of $5 \mathrm{mR} / \mathrm{hr}$ with a minimal detectable concentration (MDC) of (MDC calculated per standard methodology shown in the appendix): 


\section{- $\quad 0.3 \mathrm{mBq} / \mathrm{m}^{3}$ (threshold), $0.15 \mathrm{mBq} / \mathrm{m}^{3}$ (objective) for ${ }^{133} \mathrm{Xe},{ }^{133 \mathrm{~m}} \mathrm{Xe}$, and ${ }^{131 \mathrm{~m}} \mathrm{Xe}$ \\ - $\quad 1.0 \mathrm{mBq} / \mathrm{m}^{3}$ (threshold), $0.5 \mathrm{mBq} / \mathrm{m}^{3}$ (objective) for ${ }^{135} \mathrm{Xe}$}

R 2.2.3 The memory effect on the system shall have an upper limit of 5\%; e.g., less than $5 \%$ of the measured xenon activity shall remain in the cell at the start of the next measurement.

R 2.2.4 The loss of sample during counting shall not be larger than $5 \%$ for each measurement cycle.

R 2.2.5 The gamma-resolution shall be better than $15 \%$ full width at half maximum (FWHM) at $80 \mathrm{keV}$ and the beta resolution shall be better than $40 \mathrm{keV}$ at 129 $\mathrm{keV}$.

R 2.2.6 The shielding design shall ensure that no direct radiation from outside the shielding can reach the detector without encountering $\mathrm{Pb}$.

R 2.2.7 The system shielding shall attenuate the radiation of a ${ }^{137} \mathrm{Cs}$ source at $1 \mathrm{~m}$ distance from the detector by at least a factor of 200. Note: This would reduce the count rate of a calibration source with typical source strength $(40 \mathrm{kBq})$ to approximately 0.1 counts per second with a detector that has a cross section of $50 \mathrm{~cm}^{2}$.

R 2.2.8 The nuclear gamma and beta detectors gains shall be stable within $2 \%$ during the sample count time.

R 2.2.9 The acquisition of the sample measurement shall be less than or equal to 24 hours.

\section{F 2.3 Nuclear Detector Calibration}

R 2.3.1 The system shall provide a calibration verification method for the nuclear detector and shall be capable of reporting background and spectrum data when requested by the user.

R 2.3.2 The system shall be capable of performing a complete recalibration of the system at the station or it shall be possible to perform a concentration measurement at the station and successive calculations from a remote site.

R 2.3.3 The system shall be capable of collecting background spectra periodically when commanded by on-site or remote users. 
R 2.3.4 The system shall be capable of collecting energy spectra calibration data periodically.

R 2.3.5 The system shall limit cross talk between different detector cells (interference of a sample in a nearby detector) to less than $0.1 \%$ during calibration, i.e., the counts caused in any beta-gamma region of interest (ROI) in a detector caused by a sample in a neighbouring detector shall be less than $0.1 \%$ of the counts in the sample detector.

R 2.3.6 The system shall use a radioactive Xe gas calibration standard to calibrate the nuclear detector (typically loaded manually into the cell).

R 2.3.7 The system shall have a statistical uncertainty of the calibration sample activity measurement of $1 \%$ or less.

R 2.3.8 The gamma detector shall be calibrated for gamma energy and resolution between $25 \mathrm{keV}$ and $730 \mathrm{keV}$ with a calibration point at $\sim 80 \mathrm{keV}$.

R 2.3.9 The beta detectors shall have a minimum calibrated energy range from 10 to $1000 \mathrm{keV}$.

R 2.3.10 The detector shall be calibrated for efficiency for each of the four xenon isotopes $\left({ }^{131 \mathrm{~m}} \mathrm{Xe},{ }^{133} \mathrm{Xe},{ }^{133 \mathrm{~m}} \mathrm{Xe}\right.$ and $\left.{ }^{135} \mathrm{Xe}\right)$.

R 2.3.11 The system shall determine interference factors for all relevant interfering nuclides (i.e., interference from ${ }^{214} \mathrm{~Pb}$, and from radioxenon isotopes with each other) during the calibration.

R 2.3.12 The calculations for the nuclear detector energy, resolution, and efficiency calibration shall be documented.

\section{F 2.4 Nuclear Detector Quality Control (QC)}

R 2.4.1 The system shall be able to perform spectral acquisition using a QC source.

R 2.4.2 The system shall take a QC source measurement before each (cycle) sample measurement.

R 2.4.3 The system shall automatically remove the QC source during sample acquisition.

R 2.4.4 The system shall limit (i.e., shield) the signal of the QC sources to minimize false identification of any xenon isotope and shall not significantly raise the spectrum base-line.

R 2.4.5 The QC source shall have a peak at gamma energy of at least $662 \mathrm{keV}$ in order 
to detect small energy drifts.

R 2.4.6 The system shall use a QC source that is below the limit for exempt packaging as specified in U.S. Department of Transportation shipping standards.

R 2.4.7 The system shall provide a QC source certificate on the composition and activity of the source. If the source is used for calibration, a certificate by an accredited institution shall be provided on composition, activity, uncertainties of activity and dimensions of the active source.

R 2.4.8 The QC source shall be a sealed source per ANSI/HPS N43.6 or ISO 2919 classification designation.

R 2.4.9 The QC source to detector configuration shall be reproducible for the QC data collections.

R 2.4.10 The counting statistics of the QC measurement shall be better than 5\% (over the validity period of the QC source) for the $662 \mathrm{keV}$ peak of the ${ }^{137} \mathrm{Cs}$ source in the gamma detector.

R 2.4.11 The QA/QC source when counted shall be placed in the same location $\pm 2 \mathrm{~mm}$.

F 3 Process Control (PNNL-developed GFE software)

\section{F 3.1 Software Control}

R 3.1.1 The system shall allow a two-way communication with the user. The user shall be able to send commands to the stations (i.e., for requesting data) and perform unscheduled tasks.

R 3.1.2 The system shall provide a means to verify, remotely and on-site, the status of the Xenon International system.

R 3.1.3 The system shall use software provided by PNNL (government-furnished equipment). This software shall meet all internal PNNL quality assurance standards, e.g., software grading, development, and verification and validation requirements.

R 3.1.4 The system shall be equipped and configured to allow an operator (whether remote or on-site) to control system functions. These functions include:

(1) View sensor parameters/system status

(2) Initiate calibration validation and self-diagnostic functions

(3) Retrieve archived data. 
R 3.1.5 The system shall allow an operator (either remotely or on-site) to switch operation modes and update the system configuration.

R 3.1.6 The system shall not require user interaction to retrieve data after a shutdown and restart.

R 3.1.7 The system shall be configured to support as a minimum the following protocols and/or services:

(1) Secure Shell (SSH)

(2) Secure Copy (SCP) or Secure Shell File Transfer Protocol (SFTP)

(3) Simple Mail Transfer Protocol (SMTP)

(4) Network Time Protocol (NTP).

R 3.1.8 The system shall include a text-based menu set for the command and control functions.

R 3.1.9 The system shall include a graphical user interface (GUI) for the command and control functions.

R 3.1.10 The system shall use spectral acquisition software that allows saving the partial spectra every 2 hours so that in case of a system failure the spectrum acquired until that event is not completely lost.

R 3.1.11 The system shall use a category-5 unshielded twisted pair (UTP) cable with a RJ-45 connector (IEEE 802.3 standard) for physical connections.

\section{F 3.2 Operational Modes}

R 3.2.1 The system shall have inherent capability for the following modes:

(1) FMC: full functional operation

(2) PMC: less than full capability, but able to produce results at least intermittently (for example, operating with a failed sensor or nuclear detector)

(3) Regeneration: the system must be fully regenerated and ready to process within 8 hours

(4) Shutdown Mode: emergency and controlled shutdowns shall be operational when necessary

(5) Maintenance: maintenance is being performed on the system

(6) Failure: the system is unable to collect or record data. 
F 4 Data

F 4.1 Data Collection and Format

R 4.1.1 The system shall have a data availability rate of $95 \%$ or greater. Data availability refers to availability of the system and does not include downtime to receive new parts, delivery, availability of maintenance workers, etc. The algorithm documented in the appendix shall be used to calculate data availability.

R 4.1.2 The system shall produce, at a minimum, the following five categories of data: collection, spectral, state-of-health ( $\mathrm{SOH})$, event logger, and stable gas and activity concentrations.

R 4.1.3 The system shall archive data of all types generated or collected internally. These data shall be readily accessible locally or remotely.

R 4.1.4 The system shall generate spectral data which shall include all information required to create radioxenon activity concentrations from the information created by the detectors/sensors including background, calibration, sample spectral, and uncertainty information.

R 4.1.5 The system shall record collection data which includes all information necessary to uniquely identify a sample and the particulars of its collection (e.g., collection start/stop).

R 4.1.6 The system shall automatically generate concentration data which contain the activity and the stable gas quantification and reported in activity concentration $\left(\mathrm{mBq} / \mathrm{m}^{3}\right)$.

R 4.1.7 The system shall report and archive the results in the format of current systems (pbg file).

R 4.1.8 The system shall allow all recorded data to be downloaded from the system to an external device.

R 4.1.9 Full sample spectra shall be sent to the data center after each processing and counting cycle.

R 4.1.10 The system shall, at least daily, transmit the resulting data to the NDC either automatically or when requested, such as prior to a planned system shutdown. 
R 4.1.11 The system shall locally archive all data generated in the station after being sent to the NDC.

\section{F 4.1.1 State of Health Data}

R 4.1.1.1 The system shall be equipped with sensors and instrumentation to provide $\mathrm{SOH}$ data.

R 4.1.1.2 The SOH data shall be written in non-binary format.

R 4.1.1.3 The SOH data shall be saved every 1-30 minutes (based on a user-defined interval).

\section{R 4.1.1.4 The system shall be able to transmit the status of the state of health to the NDC.}

R 4.1.1.5 SOH data shall be sent to the data center every 2-24 hours (based on a userdefined interval).

R 4.1.1.6 The xenon collection efficiency shall be documented in the $\mathrm{SOH}$ file.

R 4.1.1.7 The SOH data shall be sufficient to track the flow of the sample through the subsystems including: gas compression, dryer, collection, separation, quantification, and nuclear detection.

\section{F 4.1.2 Event Logger Data}

R 4.1.2.1 The Xenon International system shall generate logger data (event data) which shall include a record of all commands issued by the software and by an operator.

R 4.1.2.2 The event logger data shall be written in non-binary format.

R 4.1.2.3 When an alert occurs, the system shall transmit an alarm to the NDC.

\section{F 4.2 Data Support Tools}

R 4.2.1 The system shall include a detector histogram viewer to facilitate accurate analysis of detector performance and xenon isotope samples.

R 4.2.2 The system shall include a $\mathrm{SOH}$ viewer and an event logger file viewer that include graphical user representation.

F 5 Archive System

R 5.1.1 The Xenon International system shall provide an interface for an archiving system. It is not required for the system to have a built-in archive system.

F 6 Design Constraints

F 6.1 Size and Weight 
R 6.1.1 The system shall not exceed a maximum size of: 40" wide $x$ 32" deep $x$ 80" high (threshold). The footprint will not include the uninterruptable power supply (UPS), archive system, and nitrogen bottle or generator.

R 6.1.2 The system shall not exceed a weight of 3000 pounds (threshold) 2500 pounds (objective).

\section{F 6.2 Environmental}

R 6.2.1 The system shall be equipped with a filter that will remove or filter out any particle greater than $25 \mu \mathrm{m}$ from entering the processing stream at the air inlet.

R 6.2.2 The system shall be designed so replacement and/or cleaning of the filter shall be easily performed by the local operators.

R 6.2.3 Operating conditions:

R 6.2.3.1 The system shall be able to operate in a temperature of ambient air: 50 degrees $\mathrm{F}$ (lower limit), to 95 degrees F (upper limit).

R 6.2.3.2 The temperature of intake air shall be: -40 degrees $\mathrm{F}$ (lower limit), 100 degrees $\mathrm{F}$ (upper limit).

R 6.2.3.3 The relative humidity (non-condensed) of ambient air shall be: 50\% (lower limit), 80\% (upper limit).

R 6.2.3.4 The relative humidity (non-condensed) of intake air shall be: 5\% (lower limit), 100\% (upper limit).

R 6.2.3.5 The storage temperature shall be (ambient): -24 degrees F (lower limit), 110 degrees F (upper limit).

R 6.2.4 Transport conditions:

R 6.2.4.1 The relative humidity (non-condensed) during transport shall be: 5\% (lower limit), 100\% (upper limit).

R 6.2.4.2 The temperature during transport shall be (ambient): -24 degrees F (lower limit), 110 degrees F (upper limit).

R 6.2.4.3 The system shall be designed for the following shock: short trips (less than 150 miles) over rough roads (i.e., repeated impulses at higher frequencies) and normal warehouse handling.

R 6.2.4.4 The system shall be designed to withstand the following vibration: Long trips (over 1000 miles) over smooth roads (i.e., long-duration exposure to lower frequencies).

R 6.2.4.5 The packaging shall be robust enough to prevent damage of the equipment because of thermal shock.

\section{F 6.3 Electrical}




\section{R 6.3.1 The voltage of the system shall function on single phase domestic power (threshold) and single phase foreign power (objective).}

R 6.3.2 The system shall provide a visible indicator that it is receiving input power. An example of this may be the emergency power shutoff switch has a light indicating power going to the system.

R 6.3.3 The system's power interface shall include line conditioning and surge protection.

R 6.3.4 The system's grounding, bonding, and shielding interface and installation requirements shall be in accordance with acceptable industry standards and U.S. (threshold) and international (objective) electrical codes.

R 6.3.5 The system shall include an interface to attach to a UPS to facilitate a controlled shut-down upon a sudden, unexpected power loss. The UPS is not required to be a part of the footprint.

R 6.3.6 This UPS shall ensure operation of all essential equipment for at least 15 minutes. Essential equipment will include the control computer and the electronics enclosure.

R 6.3.7 The system shall provide current overload protection and easily visible indications that a circuit breaker has been tripped.

R 6.3.8 Details of the electrical circuitry shall be included in system documentation.

F 6.4 Materials

R 6.4.1 All support structure and fabricated components (i.e., frame and housing of the system), shall be capable of withstanding 96 hours of salt spray in accordance with American Society for Testing and Materials (ASTM) B 117-03, "Operating Salt Spray (Fog) Apparatus."

R 6.4.2 The system shall not require liquid nitrogen or use of any Class I or Class II ozone-depleting refrigerants in development, operation, or maintenance.

R 6.4.3 The system shall not use proprietary resources. Computer resources, inclusive of all hardware, software, (e.g., operating system, development environment, etc.), and firmware shall be non-proprietary and non-export controlled products.

F 6.5 System Expendables

R 6.5.1 The system shall be designed to limit the number/amount of fielded expendables (e.g., no excess carrier gas).

F 6.6 Security

R 6.6.1 The internal hardware and software shall not be accessible to the operator, only to the authorized maintenance technician. 
R 6.6.2 The computer system(s) shall be protected by password(s) and/or by other similar cyber-security features.

\section{F 6.7 Safety}

R 6.7.1 The system shall allow maintenance personnel to override the interlock and other safety features as necessary for maintenance with proper warnings noted in the technical manuals.

R 6.7.2 The system shall properly mark any system element that is hazardous such as: high voltages/currents, high/low temperatures, radioactive, or chemically hazardous materials to meet U.S. safety requirement codes.

R 6.7.3 The system shall be designed to shut down without damaging personnel, anything on the outside of the system and with minimal damage to the system in the case of a power outage or a sensor failure.

R 6.7.4 The system shall be equipped with a manual emergency shutdown button.

R 6.7.5 The system shall be equipped with software safety controls that shall manage overheating and overpressure. Pending software failure, redundant safety features shall be installed such as pressure relief valves, or rupture disks. Electrical safety features are identified in section F 6.3.

F 6.8 Shutdown

R 6.8.1 The system shall not require recalibration after a shutdown.

R 6.8.2 The system shall, once the power has been restored, be able to automatically regenerate itself after a power shutdown or power outage (among others: evacuating the partial process samples).

R 6.8.3 The system shall, after an uncontrolled shut down, be able to sequence and retrieve the 2-hour spectra being acquired until shutdown.

R 6.8.4 The system shall have a controlled shutdown procedure.

R 6.8.5 The system shall be regenerated and start a collection within 8 hours after power resumed (after a power outage of less than 24 hours).

R 6.8.6 The system shall send a spectrum before any controlled shutdown.

F 6.9 Usability

R 6.9.1 The system's control panels shall be visible, easily readable, and accessible by the operator under all possible ambient lighting conditions. "Easily readable" is defined such that a government operator (with 20/20 corrected vision) can read displayed system information at a distance of 3 feet. 
R 6.9.2 The user shall be able to shut down the system either on-site or remotely. The system shall allow immediate shutdown in case of emergency and a controlled shutdown that will preserve data.

F 7 Documentation

R 7.1.1 The system shall include a mechanical drawing package including assemblies.

R 7.1.2 The system shall include an electrical drawing package.

R 7.1.3 The system shall include an electrical connection scheme.

R 7.1.4 The system documentation shall include the layout (equipment, connections, ducting, etc.) of a generic station site and equipment.

R 7.1.5 The system's documentation package shall include an operations/user manual which will include a troubleshooting guide for the system.

R 7.1.6 The system's documentation package shall include test documentation.

R 7.1.7 The system's documentation package shall include Intellectual Property releases.

R 7.1.8 The system's documentation package shall include software design and test documentation.

R 7.1.9 The system's documentation package shall include a training package which includes training material in the installation, theory of operation, operation, preventive maintenance, and demand maintenance of the system for on-site and depot maintenance for operator and maintenance personnel. The training shall be at the level targeting personnel with a high school diploma or a journeyman/apprentice-type education.

F 8 Sustainment

F 8.1 Availability

R 8.1.1 The system shall be designed to not exceed 7 consecutive days or 15 days total annually of downtime. This includes both scheduled and unscheduled downtime.

F 8.2 Maintainability

R 8.2.1 The system shall be designed in such a way that critical components can be easily accessed for troubleshooting, repair and system evolution.

R 8.2.2 The system shall be designed to minimize maintenance because of environmental conditions such as dust, condensation, humidity, etc.

F 8.3 Mean Time between Critical Failures (MTBCF) 
R 8.3.1 The Xenon International shall be designed to meet a minimum MTBCF of 8760 hours. Critical failure is defined as any failure that would cause the Xenon International to lose its collection, processing, and/or measurement capabilities and requires immediate maintenance action.

F 8.4 Mean Time between Failures (MTBF)

R 8.4.1 The Xenon International system shall be designed to meet a minimum MTBF of 4800 hours. Failure is defined as, any failure that does not cause the Xenon International to lose its collection, processing, and/or measurement capabilities (i.e., any capability less than full-mission capable (FMC) mode).

\section{F 8.5 Mean Time to Repair (MTTR)}

R 8.5.1 The Xenon International system shall be designed to meet on-site maintenance MTTR of 4 hours. This applies to "active" corrective maintenance only, and does not include time for scheduled maintenance, warm-up or cool-down cycles, or administrative and logistics delays. MTTR shall not include normal regeneration time; however, any time in excess of the required maximum regeneration times shall be included in the MTTR. Corrective maintenance shall begin upon verification of a fault by technician and includes time to:

(1) localize the fault

(2) isolate the fault

(3) remove and replace the faulted item

(4) calibrate and/or align the Xenon International (if necessary)

(5) test and check out the Xenon International (excluding the regeneration of gas system filters),

(6) initiate system start sequence.

F 8.6 Maximum Corrective Maintenance Time $\left(\mathrm{C}_{\mathrm{MX}} \mathrm{t}_{\mathrm{Max}}\right)$

R 8.6.1 The Xenon International system shall be designed to meet an on-site maintenance $C_{M X} t_{M a x}$ of 8 hours. $C_{M X} t_{\text {Max }}$ shall not include normal regeneration time; however, any time in excess of the required maximum regeneration times shall be included in the $\mathrm{C}_{\mathrm{MX}} \mathrm{t}_{\text {Max }}$.

\section{F 8.7 Support Equipment}

R 8.7.1 The system shall, to the maximum extent possible, be capable of being maintained with common hand tools, and support and test equipment. 
R 8.7.2 The system shall require no special test equipment ${ }^{1}$ to operate (threshold), and no special test equipment will be required to maintain the system for on-site Maintenance (objective). Calibration sources are an exception to this requirement.

\section{F 8.8 Transportation and Facilities}

R 8.8.1 The packaging, handling, storage, and transportation (PHS\&T) considerations shall be identified and documented (including proper markings) to ensure the system and/or components of the system shall withstand all modes of transportation used.

R 8.8.2 The system shall use reusable containers for critical spare parts and assemblies.

\footnotetext{
${ }^{1}$ Special test equipment is defined as any equipment that cannot be purchased at any major hardware retailer.
} 


\section{Appendix A}

\section{Calculations}

\section{A.1 Minimal Detectable Concentrations Calculation}

To calculate the minimal detectable concentration (MDC), the following equation is used:

$\operatorname{MDC}\left(\frac{m B q}{m^{3} a i r}\right)=\left(\frac{2.71+4.65 \sigma_{0}}{\varepsilon_{\gamma} \varepsilon_{\beta} \gamma_{B R} \beta_{B R}}\right) \frac{\lambda^{2} * T_{C}}{\left(1-\exp \left(-\lambda T_{C}\right)\right) \exp \left(-\lambda T_{P}\right)\left(1-\exp \left(-\lambda T_{A}\right)\right)}\left(\frac{1000}{V_{\text {Air }}}\right)$

where the first term takes into account the typical MDC expression using the standard deviation of the measured blank sample $\left(\sigma_{0}\right)$ with the gamma and beta detector efficiencies and branching fractions respectively $\left(\varepsilon_{\gamma}, \varepsilon_{\beta}, \gamma_{B R}, \beta_{B R}\right)$, the second term accounts for the decay of the xenon isotope during the collection time $\left(T_{C}\right)$, the processing time $\left(T_{P}\right)$ and the nuclear acquisition time $\left(T_{A}\right)$ using the decay constant for the specific isotope $(\lambda)$, and the final third term accounts for the volume of air measured $\left(V_{\text {air }}\right)$ and conversion to millibecquerel.

\section{A.2 Data Availability Calculation}

Data Availability for the Xenon International system is the ratio of data received by the National Data Center ( NDC) that can be categorized relative to the data expected to be received from that station, expressed as a percentage.

$$
\text { Data Availability }(\%)=\frac{\text { Data Received by the NDC }}{\text { Expected Data }} \cdot 100
$$

